\title{
Leadership Skills and Competencies Through the Co-Curriculum - The Singapore Management University Study
}

\author{
Kenneth Tan Siow Hui \\ Adjunct Faculty, Singapore Management University Academy, Singapore Management University, Singapore
}

\section{Email address:}

kennethtan@smu.edu.sg

\section{To cite this article:}

Kenneth Tan Siow Hui. Leadership Skills and Competencies Through the Co-Curriculum - The Singapore Management University Study. Education Journal. Vol. 8, No. 4, 2019, pp. 155-167. doi: 10.11648/j.edu.20190804.14

Received: May 20, 2019; Accepted: June 23, 2019; Published: August 8, 2019

\begin{abstract}
Student affairs professionals and those who work with students directly know in their hearts that students learn in the co-curricular arena. Unfortunately, they do not always have a way to show that to others. Once learning outcomes have been developed, the appropriate assessment measures have to be developed because stakeholders are interested in what students are able to do in college as well as what they will do when they enter the work world. Many of the skills that employers want are the very skills that student affairs professionals teach students, such as communication, problem solving, and working with others who are different from themselves. In this current environment, there are calls for student learning assessment and documentation, both in and out of the classroom. Professional associations (ACPA, 2006; ACPA/NASPA, 2010) recognize the importance of student affairs professionals' ability to assess student learning using multiple methods. Direct and Indirect Measures of measurements are used in this study to measure learning especially leadership skills and competencies. The paper will introduce examples of how these direct and indirect measures, namely a structured questionnaire and a semi-structured interview respectively, were implemented and how the results were obtained and analyzed showing evidence of learning. This research and data gleaned will make student leadership learning in higher education more robust, especially in a Singapore context.
\end{abstract}

Keywords: Leadership, Co-Curricular, Outcomes Measurement

\section{Introduction}

This report provides an analysis and evaluation of graduate outcomes that result directly from student leadership in the Singapore Management University (SMU). The study was conducted over two phases - the first phase was conducted to validate the existing list of SMU Graduate Outcomes as provided by the Office of Student Life (OSL) and the second phase was conducted to understand what the Graduate Outcomes were from the viewpoint of a student leader.

This study is arranged in chronological order - firstly, to discuss the research design and analysis of the first phase, outline the basis for the second phase, and lastly to discuss the research design and analysis of the second phase. In the first phase, definitions of the graduate outcomes were found to be insufficient, as many students gave varied responses to what they thought were graduate outcomes and the extent to which they believed they had developed these graduate outcomes.

However, we found that the variables defined in the Graduate Outcomes were neither internally consistent nor independent. The results call for a more specific definition of each variable. Hence, the second phase was conducted to identify and define skills developed from student leader and the process of developing these skills.

\section{Problem Definition}

Singapore Management University aims to be a "Different U" by bringing out a "Different you". This is done through different policies such as the mandatory internship programme, compulsory community service hours, and vibrant student life. The Graduate Outcome attempts to pave the direction for students to develop employable skills that is beneficial in the workforce. 
However, there has been no research conducted to identify the causality between the skills developed by student leaders in higher education and its effectiveness in the workplace. Hence, this research attempts to identify the skills developed by student leaders and test if student leaders use these skills developed in other environments.

\section{Study 1: Research Design}

The research focuses on the quantitative analysis of skills attained by student leaders during their term of service using the SMU Graduate Outcomes. The framework consists four elements, it aims to develop student leaders as strategic thinkers, global citizens, team players, and lifelong learners. The team noticed some similarities between the description of the variables and some attributes of the Clifton StrengthsFinder. Hence, we referred to the Clifton StrengthsFinder's questions to draft the instrument questions. The following are our interpretation of each variable based on the SMU graduate outcomes:

i. Strategic Thinker: Individuals who demonstrate the skill to integrate and apply cross-functional or interdisciplinary knowledge to resolve an issue.

ii. Global Citizen: Individuals who are able to respect diversity and empathize with people from a different community.

iii. Team Player: Individuals who display good communication skills.

iv. Lifelong Learner: Individuals who seek opportunities to develop themselves.

\subsection{Sampling Method}

Through convenient sampling, 210 student leaders in the Singapore Management University (SMU) constituent bodies were surveyed to measure skills each student leaders acquire. The survey was divided into four sections, collection of basic particulars, skills leaders felt was essential to land them in the elected or coopted role, skills used during the term of service, and skills applied during internships. Questions asked related to the four elements of the framework developed by OSL and an online survey was sent out to all students holding leadership position within student constituent bodies or student clubs.

\subsection{Statistical Analysis}

The data collected from the survey was analyzed with a computer-aided statistical tool, R-Studio.

A Cronbach alpha was applied to the scales categorized within the four skills identified in the OSL framework (Strategic Thinker, Global Citizen, Team Player, and Lifelong Learner) to validate the consistency of questions asked. Results of the various scale within the skill category were then summed to check if the Cronbach alpha is above the value of 0.7 [1-2].

Hypotheses developed for this phase include:

H0: Skills learned by student leaders of different roles are the same.

H1: Skills learned by student leaders of different roles are not the same.

A 4 by 4 correlation matrix comprising the four skills identified by OSL were constructed to conduct a cluster analysis for each of the combination of variables to test if roles can be identified from the skills learned during the student's term of office. Six scatterplots comparing each of the four skills identified by OSL and four histograms analyzing the general trend of skills were then constructed as shown below using a randomized dataset [3]. Colors indicated in the plot represents the roles students identify with. The scatterplots serve two functions, to identify general trends and correlation between skills learned in SMU, and to visually identify skills that each role learns during their term of leadership. Hence, being able to show the role which has a higher propensity to learn a certain set of skill. The histogram shows the aggregated scores of each skill from all student respondents.

\section{Validating the Graduate Outcomes}

The study surveyed a total of 210 student leaders. The data collected was then analyzed using an open-source statistical program, R Studios. The statistic package used for the analysis are "psych", "performance analytics", and "ggplot2". From this quantitative analysis, we have drawn results from the preidentified variable's internal validity, randomness of data, interdependency of data, and cluster analysis.

\subsection{Internal Validity of Variables}

The variables identified for this study are the four SMU Graduate Outcomes namely, Strategic Thinker, Global Citizen, Team Player, and Lifelong Learner. We have divided each variable into two sections with three questions each. We then calculated the Cronbach Alpha for each section and its' total Alpha score to analyze the internal validity of the variables. The recommended Alpha value to verify internal validity is above $0.7^{1}[7,21]$. The results of the alpha values are as displayed in Table 1.

Table 1. Alpha Value of Variables.

\begin{tabular}{lll}
\hline & $\begin{array}{l}\text { Raw Alpha } \\
\text { Value }\end{array}$ & Standard Alpha Value \\
\hline Strategic Thinking (Initial) & 0.76 & 0.76 \\
Global Citizen (Initial) & 0.66 & 0.66 \\
Team Player (Initial) & 0.63 & 0.63 \\
Lifelong Learning (Initial) & 0.68 & 0.68 \\
Strategic Thinking (Duties) & 0.68 & 0.68 \\
Global Citizen (Duties) & 0.24 & 0.25 \\
Team Player (Duties) & 0.17 & 0.26 \\
Lifelong Learning (Duties) & 0.46 & 0.49 \\
Strategic Thinking (Total) & 0.8 & 0.8 \\
Global Citizen (Total) & 0.5 & 0.6 \\
Team Player (Total) & 0.56 & 0.62 \\
Lifelong Learning (Total) & 0.47 & 0.5 \\
\hline
\end{tabular}

As observed, the only two variables that exhibited internal validity is Strategic Thinking (Initial) and Strategic Thinking (Total). For other variables, we observed a consistently low

\footnotetext{
${ }^{1}$ Refer to http://www.analytictech.com/ba762/handouts/alpha.htm and references from Numally, Jim C. "Psychometric theory." NY: McGraw-Hill (1978).
} 
internal validity.

The low internal validity of the variables hints at the broadness of the definitions for these variables, with the sole exception of "Strategic Thinking". This can manifest in the form of measuring multiple attributes within a single variable. Therein lies our first recommendation:

1) To narrow the definition of each graduate outcomes for analytical purposes

2) To identify skills hidden within each graduate outcome for analysis

With these recommendations, we can expect a greater variety of variables to analyze and a better internal validity for each variable.

\subsection{Cluster Analysis}

We have used a correlation matrix to perform a cluster analysis. From this study, we will be able to identify the correlation between each variable and the potential for interdependency, randomness of data, and potential for clustering.

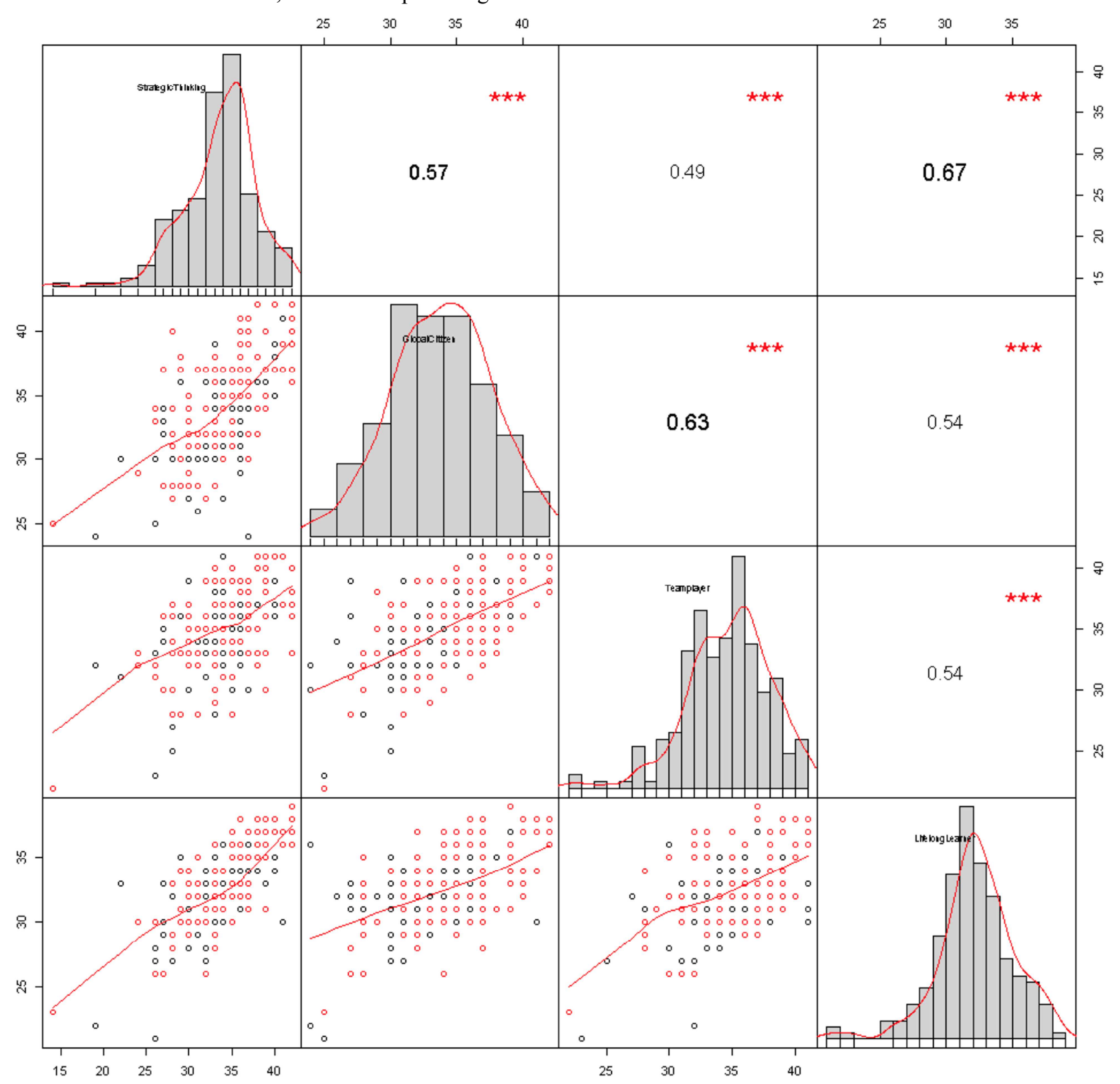

Figure 1. Cluster Analysis for Elected and Co-opted Leaders.

The first observation we can see from the correlation matrix is the randomness of data. Every variable adheres to a normal distribution which validates the randomness of the data which allowed us to proceed with the analysis [25]. Next, the correlation coefficient of each variable. The recommended inter-item correlation coefficient is between 0.2 and $0.4^{2}$ [5]. However, the correlation between the

\footnotetext{
${ }^{2}$ Briggs, Stephen R., and Jonathan M. Cheek. "The role of factor analysis in the development and evaluation of personality scales." Journal of personality 54.1 (1986): 106-148.
} 
variables as observed above is above 0.45 . This suggests interdependency between these variables.

With attention for the correlation between "Strategic Thinking" and "Lifelong Learner" at $0.67 * * *$, and "Global Citizen" and "Team Player" at $0.63^{* * *}$, we might be able to generalize the variables measured. Firstly, the abnormally high correlation between "Strategic Thinking" and "Lifelong Learner" suggests the measurement of task- orient functions of leadership while "Global Citizen" and "Team Player" might be measuring the people-orient functions of leadership. Thirdly, there is no significant signs of clustering in these scatterplots. This shows that elections make no significant impact in the skills demonstrated by student leaders. Similar observations were made on other variables.

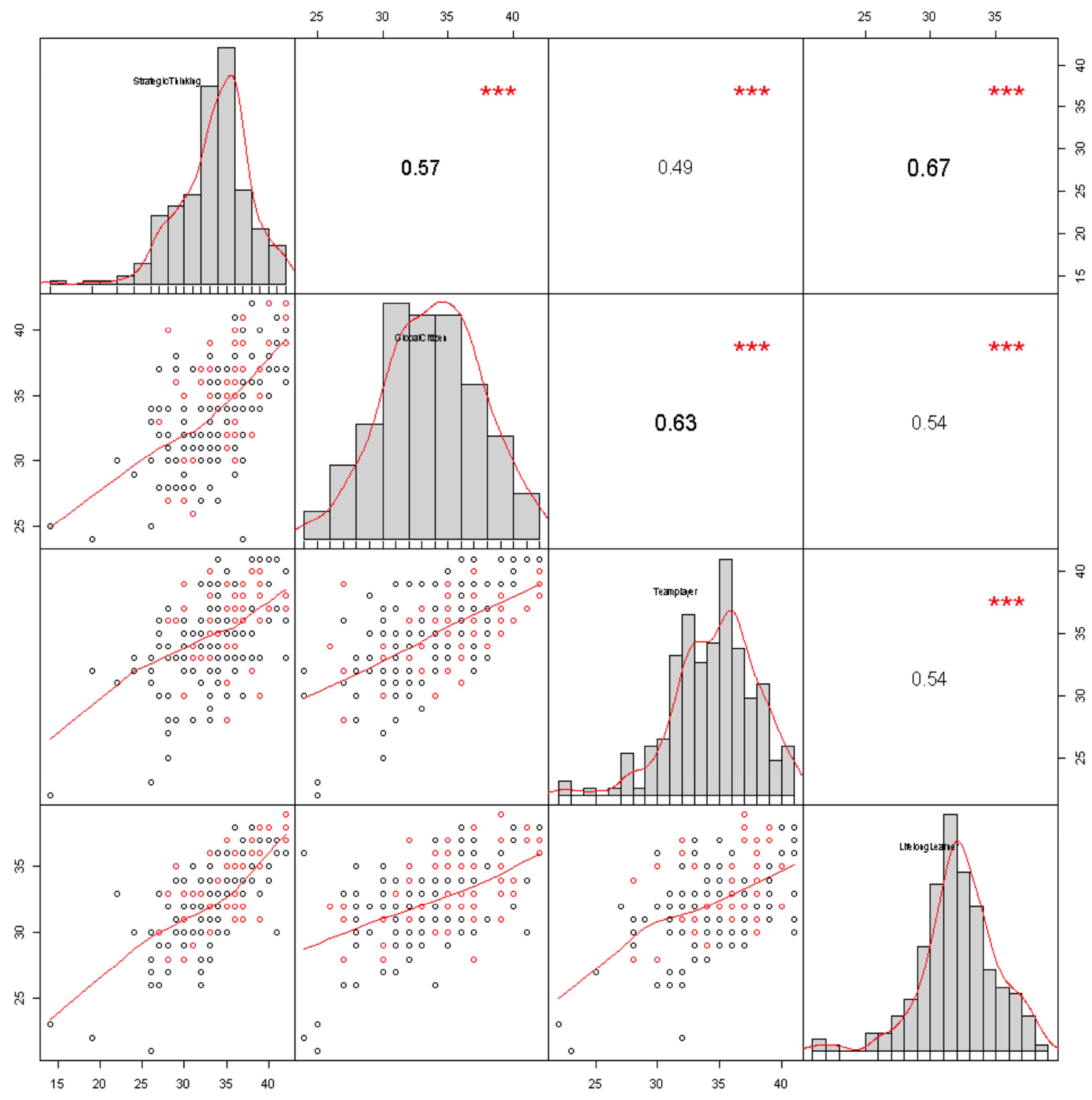

Figure 2. Cluster Analysis for Training before Term of Service. 
We witnessed little indications of clustering when we divide the survey samples based on the presence of management trainings before their term of service. This indicates the insignificant impact of trainings on skills demonstrated.

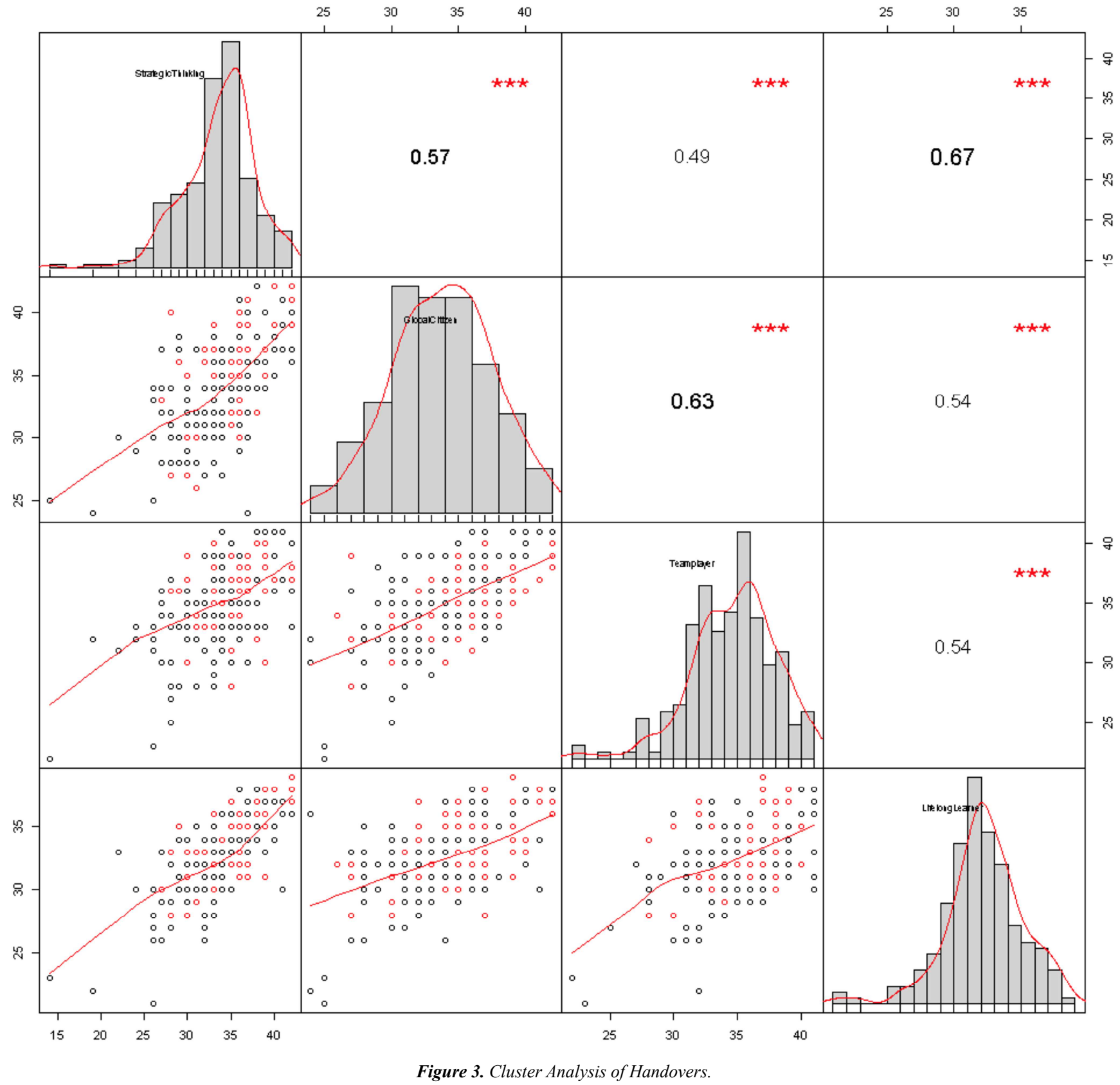

There are no visible clusters when we divided the samples by the existence of handover processes. Hence, we can infer that the handover procedures today do not have an impact of skills demonstrated by student leaders.

We observed no clusters at the scatter plot for the eight leadership roles identified. Hence, we can conclude that the roles are insignificant to the skills students demonstrate during their term of leadership. 


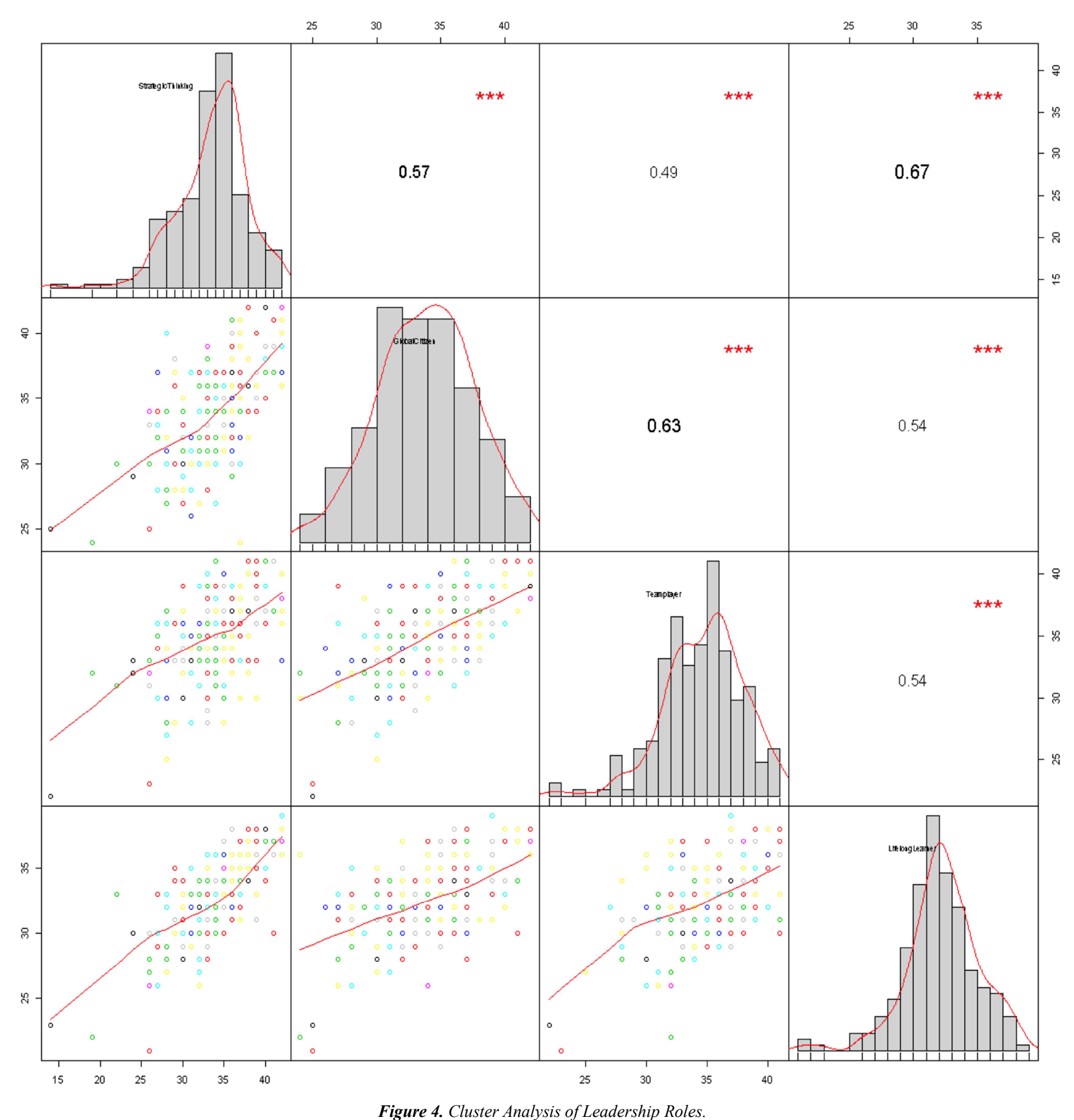

\subsection{Recommendations for 2nd Phase}

The results in the first phase indicates that the variables are both not independent nor have an internally consistent definition. Hence, a peer evaluated survey will not add clarity nor insight to the research. Therefore, the team would like to conduct a series of semi-structured, in-depth interviews to:

i. Scope and define specific skills student leaders utilize during their term of service.

ii. Identify the general attribute driving student leader's performance.

iii. Describe the Graduate Outcomes more comprehensively.
Based on the research analysis, the team has decided to approach the top two performing roles in phase 1 (the President and the Internal Relations/Liaison Director) and the bottom two performing roles (Honorary Finance Secretary and Assets/Logistics Director) across CBds and CCAs. A sample of 6 to 8 leaders were selected for this study. The interview questions [16] helped as guiding questions for the interviewer and a responsive semi-structured interview design was used.

\section{Phase 2: Research Design}

The following were research questions we identified and 
aim to address after the quantitative analysis:

1. How can we redefine the SMU Graduate Outcome to develop a set of independent and internally consistent variables?

2. What is the general factor that drives student leaders' performance for the SMU Graduate Outcomes?

3. Do trainings provided by OSL facilitate the development of the SMU Graduate Outcomes?

4. Do handover practices facilitate the development of the SMU Graduate Outcomes?

5. Do administrative duties hinder the development of the SMU Graduate Outcomes?

Question 1 will form the core of our research, aiming to plug in the gaps that the quantitative analysis has failed to answer. The initial variables are highly interdependent and we hypothesize that there is one or more fundamental factors that lead to the initial 4 variables used in the quantitative analysis. Questions 2 to 5 are validating questions - these questions have been answered in the quantitative analysis, but the interview will generate anecdotal answers to support the quantitative results. The four roles identified for interview are Internal Communications/Liaison Director and President which are the best performing roles, and Assets/Logistics Director and Honorary Financial Secretary which are the worst performing roles.

\subsection{Interview Results}

The team went through each set of interview notes, pulling out skills as mentioned by candidates. These skills were written out, and identical skills were grouped together. The first section of the interview results will aim to map out what skills were perceived to have been developed. As part of the interview also involved mapping these skills to outcomes, the first section will attempt to map out the most salient skills to outcomes mentioned by the interviewees. The second section will aim to discuss the process of skills development from their student leadership experience.

\subsection{The Skills Developed}

\section{Organizational Skills [2]:}

Rearranging tasks or information to attain objectives

Organizing skills refers to student leaders being able to rearrange task or information to attain objective. Respondents often note that they are usually involved in multiple processes and task, with each processes having different administrative procedures and requirement. They often need to be aware of such administrative procedure for them to achieve their organization goals (e.g. conducting of events, distribution of resources etc.). At times, respondents would feel overwhelmed with such requirements.

"I felt that I was quite meticulous but in the case of the school camp I felt that I actually missed out a lot of things because there was no one around to keep an eye out of how the administrative things and processes that are required for the camp and I had learned to be more organized in my processes." - Interviewee 9
To fulfill such administrative requirement, respondents would usually develop organizational skills and strategies for them to keep track of administrative process.

"I learnt about organizational skill during my term. I had to designate folders to keep things. A lot of times I had to multitask. There were many forms to fill which taught me to organize ... when an administrative process does not go through, we need to go back to locate the forms. If I don't organize it, I couldn't find it, and everything is delayed. This caused much inconvenience to the team" - Interviewee 3

2. Prioritization [14]:

Putting or acting on specific tasks or resources based on their importance or urgency

Prioritization refer to the ranking of task or issues based on importance or urgency. Respondents often note that they are faced with competing interest or concerns from various stakeholders (within respondent's team, management committee, or school offices). For some respondents, prioritization is usually required for them to carry out their function and task. Below, we can see that to distribute resources, respondents would need to first compare and later prioritize the interest of various stakeholders.

"To strategically managing resources would mean to understand what others need and using personal judgement to distribute resources. It's not merely equal distribution but to considering a wide array of variables before distribution. Prioritizing is also essential for this skill." - Interviewee 2

Respondents often will try to objectively compare and assess interest against one another before making a decision to prioritize one concern over another. Some respondent will establish a standard or criteria to determine importance and urgency. Below are examples of the various standards and criteria established by respondents:

"To be fair to stakeholders and have a good understanding of what we have to allocate and what they need. To distinguish between needs and wants." - Interviewee 3

"I don't give whatever the others want blindly... The main difference is the weighing of options after understanding them." - Interviewee 5

"My role requires me to manage both the school and the clubs' interest. This would mean that I need to be aware of the boundaries that are being set by the school and that I need to ensure that clubs do not cross that boundary." Interviewee 9

3. Negotiation [17]:

Discussion with the aim of reaching an agreement

Negotiation skills refers to respondents' ability to achieve agreement between parties through discussions. Due to competing interest between parties, respondents often that they frequently engage in negotiations to achieve consensus or agreements between parties. Negotiation skills, as understood by respondents, usually mean a need of communicating respondent's interest to other parties. This would usually involve respondents attempting to persuade or influence other parties to change their position.

"I must relay accurate information to the other members to ensure everyone knows the resources allocation... People will 
question decisions and I need to explain each decision." Interviewee 3

"I did learn negotiation skills especially with external stakeholders. I need to know my goals and then I persuade others to understand my organization's need." - Interviewee 8

Also, respondents highlighted that it is necessary for them to clearly identify the organization's interest and objective for effective negotiation. Negotiation skills would thus involve the ability to safeguard an organization interest while seeking for consensus with other parties.

"Negotiation would mean that I need to balance the interest of my organization and my stakeholders. I would need to communicate my perception of the best outcome to the stakeholders. It means not blindly giving in to my stakeholders but to balance both parties' interests and to minimize damages to my organization's interests." Interviewee 7

\section{Networking:}

Meeting individuals or groups in a formal setting in order to establish mutually beneficial relationships

Some respondents felt the opportunity to organize events had allowed them to develop socialization and networking skills. Learning of networking skills had helped some respondent to become more confident and comfortable in networking sessions.

"I now have confidence in presenting myself. When I took on the position, I was forced to speak up more and I had to be there to socialize with lots of people. I am now more comfortable to speak up." - Interviewee 5

"Because my organization is events based, I get to recruit and network with people in formal and informal occasion." Interviewee 8

However, it should be noted that not all respondent shared such sentiments. An example of this would be interviewee 2 . While interviewee 2 is required to interact and socialize with other individuals, interviewee 2 felt that training would be necessary for student leaders to adequately develop networking skills.

"There are certain things that we need help with... Social etiquette, public speaking, and hosting important people. We are not equipped to host important people. My predecessor is very helpful, but I believe more professional help is required." - Interviewee 2

5. Presentation [20]:

Showing others an idea or an outcome for them to scrutinize or consider, typically in a formal setting

Presentation skills refers to the ability of respondents to communicate their organization's opinion, ideas and position. Some respondents mentioned that they have improved their public speaking ability as they are required to regularly engage in public speaking at formal events with a large audience.

"My public speaking skills has improved. I'm able to prepare my speeches faster and am now able to improvise. This is where I become more aware about formalities, creative, and become more spontaneous." - Interviewee 1

"After I got elected, I know that I cannot avoid public speaking. How I present myself affects the organizational image and culture. I'm forced to deliver speeches at official events, that gradually built my confidence." - Interviewee 5

6. Teamwork:

Achieving goals or meet objectives in a group, especially when efficient and effective

Respondents had mentioned that significant challenges being faced by the organization were usually resolved by a group of student leaders. The ability for respondents to communicate and cooperate within a team is often salient when respondents highlight how they managed to resolve challenges. An example of this is shown by Interviewee 3 .

"I think I have learnt about group decision making. During exco meetings we have debates. There are too many opinions on topics which left us without conclusion. Hence, we have created a system to identify the right decision to be made. Most of the time, the decision maker will feel challenged because of varying feedback. With too many feedback, decision makers leave the decision to the team." Interviewee 5

7. Tactfulness [20]:

Communicating with sensitivity to others when dealing with difficult issues

Many respondents mentioned that when conveying undesirable news or opinion, there was a need to sensitive to other party opinion, interest and feelings. Respondents often developed an ability to convey such messages in a manner that was more palatable and acceptable for others.

"I had to present feedback from the students to the relevant agencies. These feedbacks came through multiple channels on a wide variety of topics. This required good observation skills and being able to understand the interests of agencies and pitching the feedback in an appropriate way" Interviewee 1

"In terms of communication, it would mean that finding a way of relaying messages to clubs in a proper manner that they will be better able to accept." - Interviewee 9

8. Empathy [13]:

Understanding the position and opinion of other individuals

Many respondents highlighted that they have developed empathy. Empathy, as defined by respondents, was found to have 2 aspects. Firstly, empathy was viewed by some respondents as an ability to understand the emotions and feelings of another individual. This can be seen in Interviewee 1 and 9 where they attempt to give emotional reassurance and comfort to other individuals.

"Throughout the entire journey, it made me develop the ability to listen. With people being emotionally unstable, I must be a better listener. The term made me comfort people more, being more sensitive and being more empathetic." Interviewee 1

"At times clubs will want to hear certain answers from us, often asking us what we can offer to the club. At times, we need to give clubs a lot assurance and they will have confidence to run their event." - Interviewee 9

Secondly, empathy was also viewed by respondents as the 
identification of interest and concerns by other parties. This usually involves the ability to view issues and problem from stakeholders' perspectives. More

"Empathy means a change of mindset and learning how to view things from the different party's perspective. It's not about what I should do, but what the others want or what would work best for the rest. I then learned how to position myself from different angles before deciding. This will help me get a more rounded perspective before deciding." Interviewee 5

"Having a listening ear and knowing the perspective of stakeholders, then being able to adapt and customize plans to cater to the needs of the stakeholders." - Interviewee 7

Aside from these skills, the team also identified more complex skills that required more than one skill mentioned. These "skills" were:

9. Resource management [4]:

Dealing with assets and resources such as finance or logistics

Resource management was a skill often developed by respondents whose primary role involves the allocation of resources. These respondents often allocate resources on principles such as "fairness" as well as seeking for the maximization of organization benefit and utility. This can be seen in the response by interviewee 2 and 3 (shown above in the discussion on prioritization). Resource management is not limited to tangible resources such as assets and finances. Other forms of resources that respondents learned to manage includes manpower and effort. This aspect of resource management is shown when the researchers sought for clarification about delegation for interviewee 5 and about process management for interviewee 6 .

"For delegation, one has to have a clear direction. It involves setting a vision or direction, weighing the available manpower and resource, and then identifying the right person for the right job." - Interviewee 5

"Process management for me it means: How can one plan and find the most convenient way to achieve a task. Especially for physical work. How can one achieve the objective with the most efficient and least effort?" Interviewee 6

10.Expectation management [15]:

Dealing with expectations that others have of you, your work, or your group

To cope with the demands and interest of multiple stakeholders on various issues, respondents were found to develop skills to manage expectations from other individuals. This would include the communicating of realistic expectation to other parties, lowering of expectation as well as rejecting the request or demands made by other parties.

"I learn to not make promises immediately and learn how to say no. Sometimes, we need to gather in numbers before saying no. We do this tactfully." - Interviewee 1

"For Managing people's expectations, what I meant by that is to drop other's expectations in a tactful manner" Interview 2

"Not promising unrealistic demands to stakeholders when working towards both the stakeholder's and my organization's interest." - Interview 7

11. Power management [3]:

Dealing with people in positions of power over the respondent

Some respondents have mentioned that they faced more difficulty in managing expectation of individuals who are possess more power as compared the respondents. Power, in this research, is not limited to legitimate power / authority. Individuals that possess more experience are also seen to possess greater power by respondents.

"The main challenge I have is to manage people who are either at the same level or better than ourselves." - Interview 2

Respondents were found to develop skills in managing differences of power. One way of coping differences in power is through building or managing relations with the individual that possess power. This can be seen in responses by interviewee 4 .

"Instead of following orders, we must manage relationship with superiors. I realized that the way superiors view the issues is different from how a student leader views it... It's different from managing student leaders because we have similar perspectives as student leaders. Superiors have more experience and very different interest." - Interview 4

12. Conflict management [24]:

Dealing with discussions that are emotionally charged

While respondents have highlighted that if they are unable to resolve or manage the competing interest between parties of disagreement, disagreements can potentially escalate to situations of emotionally charged conflict. In such situations, respondents mentioned that they would need to cope with hostile emotions and threat from other individuals. Respondents mentioned that they had developed skills in managing the emotions of others to deescalate such conflicts, or provide systems for communication without exciting emotions

"I used the skill of conflict management. When a club a member was unhappy with the exco and wrote an email to us, making allegations about the exco ... We held the meeting a few weeks after the email. We went to collect information to investigate if there were basis for his claims. We got mediators and all parties involved to a meeting to iron out issues." - Interviewee 4

"There was once that my committee was not communicating. We then organized a structured feedback session to help break the ice and dispel conflicts." Interviewee 8

Situation of conflict was found to potentially create stress and anxiety for student leaders. This is shown in the case of interviewee 9, who mentioned that $\mathrm{s} /$ he developed ways to better manage stress and emotions when facing situation of conflict.

"Overall, I feel that the experience is overall beneficial, and it help to develop myself like I can better handle rejection, conflict and unforeseen circumstances. And I learn not to panic when problem arises" - Interviewee 9 
Because the latter four skills require more than one skill and are not skills in themselves, the team decided to use these management issues as a way to map out the eight aforementioned skills. The way these skills are plotted out are depicted in the following page:

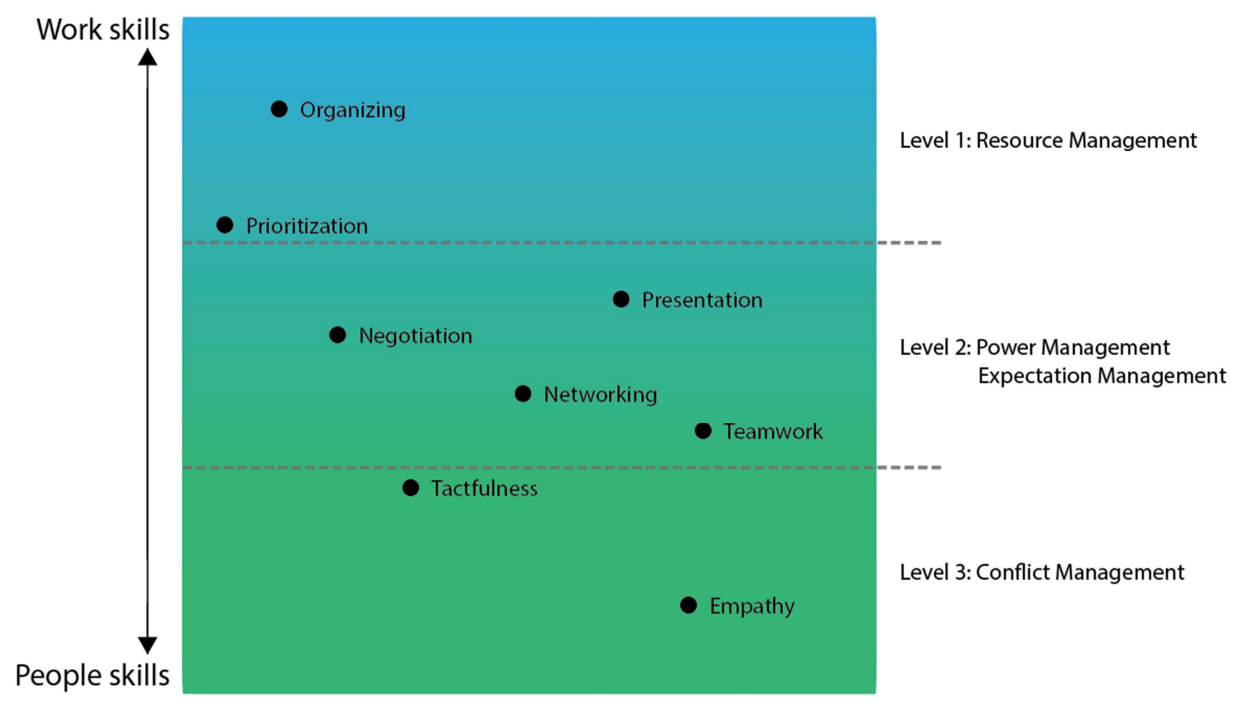

Figure 5. Mapping of Skills and Levels.

Each level (on the right) corresponds to a management issue. They were arranged in order of difficulty - for instance, resource management dealt purely with resources excluding people; power and expectation management dealt with people working together or collaborating; finally, Level 3 corresponds to dealing with emotional people in discussions, which requires more than simply working with a few people of different backgrounds.

After that, each skill was mapped out onto a grid less matrix. This was to account for the fact that all skills are to some extent needed for all levels of management issues, while allowing for the more salient skills to emerge. For example, in Level 2, expectation management requires more of negotiation than tactfulness, even though tactfulness would be a useful skill - skills on Level 2 are in some sense hybrid, combining a mix of work-related skills and people skills. The skills are not arranged in any particular manner across the grid as there is no horizontal axis.

\subsection{The Process of Skills Development}

The process of skills development of a student leader is very consistent with the SECI Model [22] which attempts to explain learning and knowledge creation. While SECI is designed for individuals, organizations have adopted the model for organizational knowledge management.

The model explains the production, evolution, and transformation of knowledge as the individual goes through the socialization, externalization, combination, and internalization process. By converting tacit knowledge to explicit knowledge and vice-versa, knowledge can be retained and created.

Phase 1: Selection

There is a self-selection effect of student leaders. They possess certain skills and traits that increase their chances of being elected or recruited into the team. All student leaders experienced some form of campaigning and networking activities to increase support or legitimacy for the role they took on.

\section{Phase 2: Induction}

There are 2 important processes in this phase, trainings provided by the organization and handovers from predecessors of the role. Most student organizations conduct their handover socially.

Little made references to the handover documents passed on to them. Most handover processes are conducted socially without documentation. Respondents also indicated their preference of a mentor as compared to a handover document.

"Mentorship will be good, handover replaced by mentorship until March." - Interviewee 3

"I think a mandatory shadowing will be good for the new batch of leaders." - Interviewee 6

"I think it will be good if there is a documented handover process with guided mentorship." - Interviewee 8

"If I were to go through this again I would probably prefer to have OSL to follow through more instead of me approaching to them. At times, I hoped that OSL give some prompt and would inform us about some of the school regulation which are not made known to us." - Interview 9

This, however, requires the predecessor and successor to have a neutral or positive relationship. We have not gathered sufficient evidence that this can work in the event of a hostile succession. This process models the socialization phase of the SECI model. The transfer of tacit knowledge between two individuals is best done socially.

\section{Phase 3: Execution}

Many respondents stated that they learn most from the job itself. Adopting the learn-by-doing approach, student leaders shared that they familiarize themselves with routines and are becoming more proficient in their tasks gradually. There is consensus that respondents "get used" to their role before 
summer, spanning between three and four months into their role. This is more distinct for individuals who described that their roles are more administrative than social.

"Nothing can really prepare you for the job except for the job itself." - Interview 4

"However, most of the things you have to learn from your mistake. You cannot you prepare yourself for this, it is something that you have to experience yourself." - Interview 9

This process models the externalization phase of the SECI model where individuals apply their knowledge to the job. This aims to transfer the individual's tacit knowledge into explicit knowledge. One way to improve learning is to adopt quarterly reviews to ensure that the individual learns from the experience. This is supported by our interviews as none of the participants reflected about their personal development prior to the interview.

Phase 4: Problem-Solving

Only some respondents reported their experience of addressing problems beyond their job scope. Nevertheless, all respondent who reported such a phenomenon shows indications of the use and combination of different skills to develop a solution. Both task specific and people skills were demonstrated for participants who indicated the occurrence of such an event.

"When my team set-off to lead the organization, I thought I must be very strict and rigid. I was very work-oriented, and we lost the joy of why we first step up. What we need to solve is not the day-to-day operations but the culture of the organization. There was a gap between my organization and its stakeholders. We then aim to bridge the gap and increase the personal touch with our stakeholders, abandoning the rigid approach. I realized that regardless the size of organization, we realized that the personal touch is required. Through this personal touch, we can gain the trust of the member groups. It's not the tough authority that gets things done. How changing my approach can help in getting things done." - Interview 5

This models the combination phase of the SECI model where individuals use interdisciplinary knowledge to solve a problem. This requires the customization and combination of different skills and experiences. This is evident during negotiations when student leaders claimed to have used different skills such as prioritization, empathy, and presentation to achieve their objectives.

Phase 5: Consolidation \& Application

There is a trend for the applicability of skills. Respondents indicated that work-related skills are more applicable during their internships and they were not able to apply peoplerelated skills during their internships. This is largely due to the difference in autonomy and power in the environment they operate in. Respondents also reported the application of hybrid skills to manage expectations. These skills include negotiation, networking, presentation, and teamwork.

"Internships are more fixed and structured. Student leadership is not; you can talk about anything. As a student leader, when you interact with the office, you are regarded as a stakeholder, they will still listen to you. [School] offices will give you feedback, and try to influence you or change your mind. As an intern, you will just be shot down" Interviewee 1

"Internship?! Not really. There were a lot of processes that you felt were not good, but you need to be more careful with proposing ideas. Your job is to follow what the boss says. Skills I've learned wasn't very useful." - Interviewee 2

"I didn't use these skills for a living but soft skills... ... I will learn it. It's not the most helpful skill in my internship. It might come in useful in the future but I'm not sure. I don't need a leadership position to learn these soft skills. [I guess] these are skills that we can pick up along the way? We don't need a 1-year commitment to fully develop these skills." Interviewee 6

Skills learned from student leadership is useful in internships:

"I learned how to plan using Microsoft Excel and seeking approvals. Resource allocation is something I learned as well. I must be meticulous with the resource I have. I also need to maximize my organization's utility. This whole experience helped me to be more organized. This is especially helpful during internship where I must be meticulous." - Interviewee 3

"I have not applied these skills directly during my internship. However, learned how to assess the emotions of my colleagues better. This helped me navigate around the social situations in the offices more effectively." Interviewee 5

"I have applied these skills during my internship. I negotiated with my stakeholders to attain my organization's objective. This, I learned from the role. I am also better able to manage resources at my internship." - Interviewee 7

From this, we note that there is a knowledge retention deficit from both the organization and individual. Skills learned from student roles has limited immediate applicability to internships.

\section{Recommendations}

The quantitative study calls for a better definition of the graduate outcomes. In this study, we have identified and defined skills that students claimed to have learned from their experiences as student leaders. Nevertheless, there is more that can be done to improve the quality of student leadership and enhance the learning experience of students. Comparing the graduate outcomes and the skills identified by the interview, we suggest to have subsections within the graduate outcomes. Alternatively, graduate outcomes can be redefined and tailored to the skills learned by student leaders based on bottom-up feedback from student leaders. This will present a more accurate depiction of skills use and developed as students undergo the SMU student-life experience.

Next, there is consensus from the interview responses, showing that extended and guided mentorship procedures are preferred as compared to handover documents. This is consistent to the SECI Model, stating that tacit knowledge 
transfer is best done by social processes. Interviews with student leaders suggested a three-month mentorship period after taking over and have predecessors to stay and mentor their successors from January to March. In contrary to the suggestion, we think it is more feasible to prepone the selection of candidates. By selecting the successors by September, it binds predecessors to their duties while keeping successors enthusiastic. Hence, providing the office greater autonomy over the handover and mentorship process between the predecessor and successor. Additionally, there is a call for specific formal trainings to be provided to all student leaders on an optional basis. Interviewees shared that they are unable to host trainings at a specific level due to the limited interest. However, by expanding the target audience to include all student leaders on an opt-out basis, the school can achieve the required scale to host formal skill trainings or leverage on existing student interest groups to conduct these skill trainings to improve the performance of student leaders.

Finally, we propose to conduct a study on leaders who have graduated and gotten a job. From the interviews, participants shared that skills they've developed from student leadership had limited applicability during their internship. This is largely the result of the lack of responsibility and autonomy given to interns in the private sector. However, this might not reflect the applicability of these skills as a full-time employee. Hence, another study should be conducted on student leaders who has recently graduated to assess the applicability of these skills as an entry-level employee.

\section{Conclusion}

Student leadership can develop employability skills if the institution place sufficient emphasis on specific skills it intends to develop from these leaders. Interviews with student leaders gave us clarity in the skills they developed and applied over their term of service. This allowed us to categorize skills into three main categories; task-based, relationship-focused, and hybrid skills. This method of developing and defining skills increases the accuracy of its definition due to the bottom-up, user-centric approach. Hence, improving its applicability for future quantitative research.

We have also observed that interviews from student leaders reported that their development during their term of service mirrors the SECI model. This has implications on handover processes and trainings for student leaders. Due to the preference of a more social process for handovers, we suggest for the elections fever to be brought earlier into their term to facilitate and mandate effective handovers and onthe-job trainings. Formal trainings for specific skills identified in this study can be provided to all student leaders. Various platforms can be used. This includes but are not limited to skills-based Co-Curricular Activities, the annual leadership symposium, and additional workshops hosted throughout the year. Skills training can also be tailored to the general phase of development for the student leaders based on the SECI model. Skills developed from these trainings can then be included into the student's co-curricular records.

Finally, the applicability of skills developed during student leadership cannot be observed while students are still undergraduates. This is due to their role as an intern as they are given little job autonomy and formal responsibilities. The research can be better supplemented by interviewing graduates who are already in the workforce, and had served as a student leader when they are undergraduates.

\section{References}

[1] Anderberg, M. R. (1973). Cluster analysis for applications. Office of the Assistant for Study Support Kirtland AFB N MEX.

[2] Archer, W., \& Davison, J. (2008). Graduate employability. The Council for Industry and Higher Education.

[3] Bouquet, C., \& Birkinshaw, J. (2008). Managing power in the multinational corporation: How low-power actors gain influence. Journal of Management, 34 (3), 477-508.

[4] Bridgstock, R. (2009). The graduate attributes we've overlooked: Enhancing graduate employability through career management skills. Higher Education Research \& Development, 28 (1), 31-44.

[5] Briggs, S. R., \& Cheek, J. M. (1986). The role of factor analysis in the development and evaluation of personality scales. Journal of Personality, 54 (1), 106-148.

[6] Coughlan, M., Cronin, P., \& Ryan, F. (2009). Survey research: Process and limitations. International Journal of Therapy and Rehabilitation, 16 (1), 9-15.

[7] Cronbach, L. J. (1951). Coefficient alpha and the internal structure of tests. Psychometrika, 16 (3), 297-334.

[8] Gallup Inc. (n.d.-a). Communication. Retrieved June 28, 2018, from

https://news.gallup.com/businessjournal/643/Communication. aspx

[9] Gallup Inc. (n.d.-b). Empathy. Retrieved June 28, 2018, from https://news.gallup.com/businessjournal/667/Empathy.aspx

[10] Gallup Inc. (n.d.-c). Harmony. Retrieved June 28, 2018, from https://news.gallup.com/businessjournal/676/Harmony.aspx

[11] Gallup Inc. (n.d.-d). Learner. Retrieved June 28, 2018, from https://news.gallup.com/businessjournal/694/Learner.aspx

[12] Gallup Inc. (n.d.-e). Strategic. Retrieved June 28, 2018, from https://news.gallup.com/businessjournal/718/Strategic.aspx

[13] Grant, L. J., \& Kinman, G. (2013). The importance of emotional resilience for staff and students in the "helping" professions.

[14] Hager, P., \& Holland, S. (2007). Graduate attributes, learning and employability (Vol. 6). Springer Science \& Business Media.

[15] Johns, G., \& Saks, A. M. (2001). Organizational behaviour: Understanding and managing life at work.

[16] Kvale, S. (1994). Interviews: An introduction to qualitative research interviewing. Sage Publications, Inc. 
[17] Mallough, S., \& Kleiner, B. H. (2001). How to determine employability and wage earning capacity. Management Research News, 24 (3/4), 118-122.

[18] McArdle, S., Waters, L., Briscoe, J. P., \& Hall, D. T. T. (2007). Employability during unemployment: Adaptability, career identity and human and social capital. Journal of Vocational Behavior, 71 (2), 247-264.

[19] McLaughlin, M. (1995). Employability skills profile: What are employers looking for?

[20] Moore, T., \& Morton, J. (2017). The myth of job readiness? Written communication, employability, and the 'skills gap'in higher education. Studies in Higher Education, 42 (3), 591609.

[21] Nunnally, J. C., Bernstein, I. H., \& Berge, J. M. ten. (1967). Psychometric theory (Vol. 226). McGraw-hill New York.
[22] Rice, J. L., \& Rice, B. S. (2005). The applicability of the SECI model to multiorganisational endeavours: an integrative review. International Journal of Organisational Behaviour, 9 (8), 671-682.

[23] Steckler, A., McLeroy, K. R., Goodman, R. M., Bird, S. T., \& McCormick, L. (1992). Toward integrating qualitative and quantitative methods: an introduction. Sage Publications Sage CA: Thousand Oaks, CA.

[24] Thomas, K. W. (1992). Conflict and conflict management: Reflections and update. Journal of Organizational Behavior, 13 (3), 265-274.

[25] Var, I. (1998). Multivariate data analysis. Vectors, 8 (2), 125 136. Contact email: kennethtan@smu.edu.sg (Kenneth Tan Siow Hui). 